John E. Madias

\section{Speckle tracking in patients with atypical Takotsubo syndrome: seek, and ye shall find!}

Accepted: 4 November 2015

Published online: 20 November 2015

(C) Springer-Verlag Berlin Heidelberg and ESICM 2015

Dear Editor,

The report by Cinotti et al., published online ahead of print on 26 October 2015 [1], about the employment of serial transthoracic echocardiography (TTE)-based speckle tracking analysis (STA), aiming at detecting early systolic function impairment, in 46 patients with severe aneurysmal subarachnoid hemorrhage (SAH) is intriguing, because it brings forth again the nagging issue whether Takotsubo syndrome (TTS) in general and its atypical varieties in particular [2-5] are much more prevalent than currently clinically recognized. Using a "proactive" (seek, and ye shall find) approach in detecting the disease, consisting of carrying out STA on days 1, 3, and 7 of hospitalization in 46 patients with severe SAH and comparing the data with STA from a control group of normal subjects matched for age and gender, the authors found a severe decrease of the left ventricular (LV) global longitudinal strain in 17
(37\%) patients with SAH on day 1, while the LV ejection fraction (LVEF) was preserved, with normalization of STA by day 7, in keeping with experience with the TTS phenotype, where LVEF normalizes or reveals major improvement by the end of the first week after admission. The authors concluded that STA "could be used for sensitive detection of stress cardiomyopathy" and that "this is critical because cardiac impairment remains a major cause of morbidity and mortality after SAH" [1]. This study reminds me of the work of Korean investigators who prospectively carried out serial TTE in patients admitted to the medical intensive care unit and detected TTS in $21 \%$ [6], and $28 \%$ [7], of patients with critical illness. Accordingly, although the frequency of TTS, associated with depressed LVEF, in patients with SAH when diagnosed by routine clinical evaluation in retrospective studies has been described to be approximately $1 \%$ [8], it will be found to be much higher in prospective studies employing serial TTE. Moreover the frequency may be found to be even higher if mild atypical forms of TTS are considered [4].

\section{References}

1. Cinotti R, Piriou N, Launey $Y$ et al (2015) Speckle tracking analysis allows sensitive detection of stress cardiomyopathy in severe aneurysmal subarachnoid hemorrhage patients. Intensive Care Med. doi:

10.1007/s00134-015-4106-5
2. Madias JE (2013) Is the "rare" Takotsubo syndrome a common affliction? Am J Cardiol 111:778

3. Madias JE (2013) "Thinking outside the box" on Takotsubo syndrome. Am J Cardiol 111:1832-1833

4. Madias JE (2014) Forme fruste cases of Takotsubo syndrome: a hypothesis. Eur J Intern Med 25:e47

5. Madias JE (2014) Why the current diagnostic criteria of Takotsubo syndrome are outmoded: a proposal for new criteria. Int J Cardiol 174:468-470

6. Yang HS, Kim HJ, Shim HJ et al (2015) Soluble ST2 and troponin I combination: useful biomarker for predicting development of stress cardiomyopathy in patients admitted to the medical intensive care unit. Heart Lung 44:282-288

7. Park JH, Kang SJ, Song JK et al (2005) Left ventricular apical ballooning due to severe physical stress in patients admitted to the medical ICU. Chest 128:296-302

8. Abd TT, Hayek S, Cheng JW, Samuels OB, Wittstein IS, Lerakis S (2014) Incidence and clinical characteristics of takotsubo cardiomyopathy postaneurysmal subarachnoid hemorrhage. Int J Cardiol 176:1362-1364

\section{J. E. Madias ( )}

Division of Cardiology, Elmhurst Hospital Center, 79-01 Broadway, Elmhurst,

NY 11373, USA

e-mail: madiasj@nychhc.org

Tel.: (718) 334-5005

\section{J. E. Madias}

Icahn School of Medicine at Mount Sinai, New York, USA 